\title{
Modeling of Motors for Electric Vehicles
}

\author{
S. Jensie Anita, K. Boopathy
}

\begin{abstract}
In the present scenario, the reduction of greenhouse gases is mandatory in order to create a better environment. Since the pollution levels are rising at an alarmingly high rate the need to reduce the green-house emissions is of utmost importance, to make the earth a better place to live in. usage of fossil fuels for transportation is a major cause for pollution and emission of harmful gases into the atmosphere. Studies show that in 2017 alone an average of 1873 metric tons of Greenhouse gases was released into our atmosphere by the transportation sector alone. This level of pollution continues to accumulate over the years causing devastating changes to our atmosphere and in turn gravely affect our climate destroying our habitat and threatening our survival. The resulting climate changes and its unprecedented fluctuations that have been observed stand to prove that pollution is not something to be ignored the slightest. To overcome this, one of the best first steps to start with prefers Electric vehicles over the conventional Internal Combustion Engines. By switching over to Electric vehicles the pollution levels can be controlled to a greater extent. Due to the relative ease of manufacturing and application specific interest cause the electric drives to be used in different applications and over the years various electric drive systems like DC, Permanent Magnet Synchronous Motor(PMSM),Brushless Direct Current Motors (BLDC)and switched reluctance motors (SRM)were developed. But each motor had its own advantages like better torque curve, better efficiency, lower power consumption and limitations like commutation issues, triggering, shorter life-span, high maintenance, more cost etc. which made it application specific rather than being all purpose. Different type of electric motor systems had different advantages that made it a better choice in specific applications. Even though this limited the use of these systems, this situation allowed the electric motor system to evolve into many types, each with their unique application in mind. This gives us an opportunity to have a vast selection of systems in front of us and enable us to choose the best system that meets our requirements. This paper reviews the different types of motors used in Electric vehicles based on the discussions and conclusions of various reputed journals consumption.
\end{abstract}

Keywords: Electric Vehicle, Green house gases, Switched Reluctance Motor.

\section{INTRODUCTION}

The electric vehicles are not new to this world. The concern on pollution control and technological advancements has given EVs a tag of future mobility.

Electric vehicles came into existence in mid 19th century. It lost its popularity due to higher cost, frequent charging of batteries, range anxiety and lack of interest of consumers. Resurge again because of the problem associated with the

Revised Manuscript Received on December 11, 2019

S. Jensie Anita*, Assistant Professor, Department of EEE, AVIT, Chennai, India.

Dr. K. Boopathy, Professor, Department of EEE AVIT, Chennai, India. E-mail: boopathyk@avit.ac.in.org fuel vehicle with the environment. By switching to electric vehicles environmental pollution can greatly be reduced. Studies show that $25-30 \%$ of the atmospheric pollution is caused from the transportation sector alone. To makes the adoption of electric vehicles much more important. The main advantages of the Electric vehicles are No tailpipe emissions, they are quick and quiet, lower running costs and fewer components [1]. Even if the Electric vehicle is to be exclusively fueled by the electricity generated by coal the emission profile is still better than the internal combustion vehicles. Adopting an electrical system also provides with many cleaner alternative power sources to depend on, and if their development were to be brought to a considerably higher degree, the dependence on fossil fuels can be reduced to great extends.

\section{METHODS AND MATERIALS USED IN ELECTRIC VEHICLES}

As the performance and efficiency of an EV based the electric motor which plays a essential role in Electric vehicles. The rapid development in the field of Battery technology, Production methods, Power electronics and its control techniques have paved way for various types of electric drives to be used in Electric vehicles. With the increasing demand in fossil fuels and hike in their price, the affordability of these systems is decreasing rapidly. This situation resulted in a hike in the demand for better alternatives and boosted the electric vehicle industry that was previously almost abandoned. The resulting researches and developments came through with many improvements in existing models and manufacturing methods [2]. Motors being a vital component in these drive systems the improvements in this field increased rapidly. Such types of electric motors should have the characteristics like good efficiency, high starting torque, high power density, etc.

\section{A. DC Motor}

The high initial torque of the DC motor makes it suitable for the traction application.

The main advantages of these types of motor are the withstanding capability of the motor even when there is sudden increase in load. DC motors are simpler in construction and working and also have two basic types, namely shunt and series DC motor and it shown in fig. 1 . These types of motors have constructions relatively simpler and mostly depend on integrated mechanical systems more than electronic manipulation making these types of systems easy to control due to the only controlling factor being the power supplied making the controls simpler. However, it requires relatively high maintenance because of the brushes and commutators. 


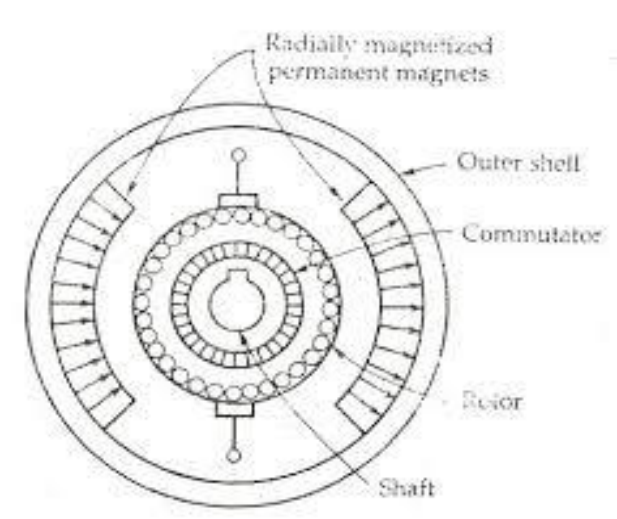

Fig. 1. Model of DC motor

\section{B. Calculating the Requirements of Mechanical Power}

Electrical power is converted to mechanical power and addition to losses of frictional as well as power losses (Joules/sec).

Pelectrical $=$ Pmechanical $+\mathrm{P}$ loss

Actually, rate of doing work is called as power or energy. Power or energy is the product of force, multiplied by distance per unit for linear. In rotational, power is for per unit time the product of torque multiplied by rotational distance.

Protation $=\mathrm{M} \times \omega$

Protation -mechanical power for rotational

$\mathrm{M}$ - torque

$\omega$ - velocity

Angular velocity is rev/min (RPM). The calculation of Protation, the velocity converts to $\mathrm{rad} / \mathrm{sec}$ units. It is achieved by multiplying the velocity with constant $(2 \times \Pi) / 60$ :

$\omega \mathrm{rad}=\omega \mathrm{rpm} \times\left(2 \prod\right) / 60$

Considering involvement of these units while the power calculation. Conversion tables are very useful for this principle. Such a reference is used to convert the torque-speed product to power. Conversion factors for commonly used torque and speed units are tabulated. the conversion of RPM to $\mathrm{rad} / \mathrm{sec}$ is obtained by above factors, where applicable.

\section{BLDC Motor}

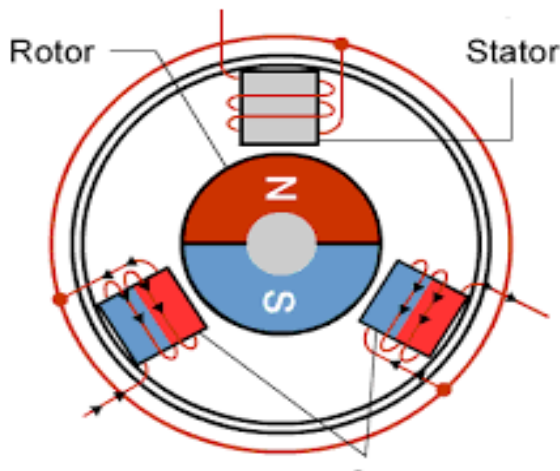

Stator

Fig. 2. Model of BLDC Motor

It is quite similar to the DC motors but with permanent magnets. The BLDC a motor are represent in fig. 2 are maintenance free because of the electronically done commutation. The BLDC [10] motors have certain characteristics like high starting torque, high efficiency and high-power density etc. These types of motors are widely preferred in electric vehicles because of these characteristics. They find its applications in electric cycle, three wheelers and scooters. The main drawback of this kind of motor is the high cost because of the permanent magnets. This also brings in the reliability of the magnets to retain its magnetism into question. And due to the thermal properties, these motors cannot be overloaded beyond certain limit [3].

\section{Brushless Motors Parameterization}

Various motor information:

$\mathrm{Kv}=$ Revolution per minute per volt.

$\mathrm{Rm}=$ the resistance in motor in Ohms.

Io $=$ Current at no load

From Hender shot and Miller:

$\mathrm{Kq}=30 /(\mathrm{pi} \mathrm{Kv}), \mathrm{Kq}=$ constant torque

At current (I):

$\mathrm{RPM}=\operatorname{Kv}(\mathrm{I}-\mathrm{Io})$

$\mathrm{Q}=\mathrm{Kq}(\mathrm{I}-\mathrm{Io})$

The Efficiency of the Motor:

$\eta=(\mathrm{V}-\mathrm{I} \mathrm{Rm})(\mathrm{I}-\mathrm{Io}) /(\mathrm{V} \mathrm{I})$

Voltage and current are termed as V,I respectively.

Current at Max Efficiency:
$\operatorname{Imax}=\operatorname{sqrt}(\mathrm{V}$ Io/Rm)

Torque at Max Efficiency:

Qmax $=$ Kq (Imax - Io)

RPM at max eff.

$\mathrm{RPMmax}=\mathrm{Kv}(\mathrm{V}-\operatorname{Imax} \mathrm{Rm})$

\section{Current at Max Power Output:}

$\mathrm{Ip}=(\mathrm{V}+\mathrm{Rm} \mathrm{Io}) /(2 \mathrm{Rm})$

Torque at max power output

$\mathrm{Qp}=\mathrm{Kq}(\mathrm{Ip}-\mathrm{Io})$

RPM at max power output.

$\mathrm{RPMp}=\mathrm{Kv}(\mathrm{V}-\mathrm{Ip} \mathrm{Rm})$

\section{Motor Maximum Efficiency:}

$\eta_{\max }=\left[1-\right.$ Sqrt $\left.(\text { Io Rm / V ) })^{2}\right]$

Torque at max efficiency:

Qmax $=$ Kq (Imax - Io)

RPM at max eff.

$\mathrm{RPMmax}=\mathrm{Kv}(\mathrm{V}-\operatorname{Imax} \mathrm{Rm})$

Using this equations: A device is to be shifted total device drag is known: Rt (Total resistance).Minimizing output is chosen from: Installation requests, material limitations Thrust >>Rt (N) Torque: Motor can run at necessary RPM. Maximum design speed: Vmax $(\mathrm{m} / \mathrm{s})$ Hence: Required propeller thrust power:

$\mathrm{Pp}=$ Rt $\mathrm{x}$ Vmax 


\section{E. Permanent Magnet Synchronous Motor (PMSM)}

These motors are similar to that of the BLDC motor that have permanent magnets on the rotor. These motor exhibit similar characteristics that of BLDC motor like high efficiency and high-power rating. It is best suitable for high power applications like cars, buses. These motors are very costly than the BLDC motors.

\section{F. Three Phase Induction Motors}

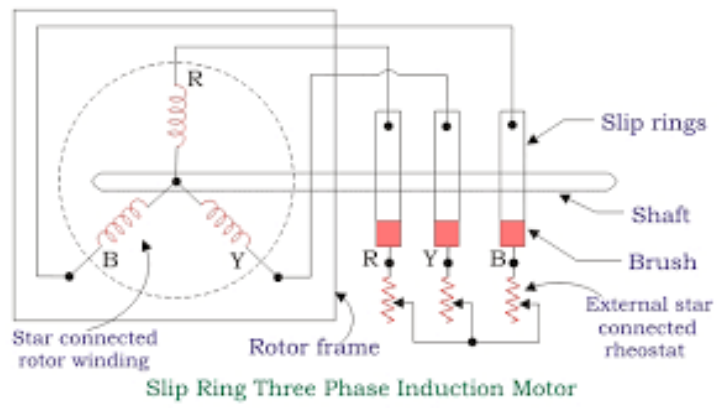

Fig. 3. Model of IM motor

Unlike the DC series motor the Induction motors do not have high starting torque. But it can be altered by using various control techniques like v/f method and even separate starter systems are used to bring this type of motors up to speed. The main drawback of these motor is complex inverter circuit involved which makes the control of motor a difficult task. The Three phase induction motors is displays in fig. 3. and run due to the principle of slippage and a phenomenon in which the rotor always tries to catch up and synchronize with the stator, this kind of systems are preferred in applications where constant speed and torque is ideal. Also this type of motors even though preferred more in industrial applications they do not make a prime candidate in the field of electric vehicles [9].

\section{G. Torque Equation of Three Phase Induction Motor}

Automated The 3 phase induction motor (IM) torque is based on the three factors as below:

- magnitude of rotor current,

- The rotor interaction flux of IM and which is responsible for the emf production of IM rotor.

- The power factor (PF) of 3 phase IM rotor

From these factors, we get the equation of torque as:

\section{$T \propto \phi I_{2} \cos \theta_{2}$}

Where, $\mathrm{T}$ is the IM torque, $\varphi$ is flux which is in charge to emf production, $\mathrm{I} 2$ is current that produced by rotor, $\cos \theta 2$ is the rotor PF.

Here, $\varphi \propto \mathrm{E} 1$

Transformation ratio $(\mathrm{K})$ :

It is the percentage of secondary voltage to primary voltage of that.

$$
\begin{aligned}
& K=\frac{E_{2}}{E_{1}} \\
& \text { or, } K=\frac{E_{2}}{\phi} \\
& \text { or, } E_{2}=\phi
\end{aligned}
$$

$\mathrm{I}^{2}$ is fraction of rotor EMF which induced below running condition $\mathrm{SE} 2$ to total impedance, $\mathrm{Z} 2$ of rotor side,

i.e $I_{2}=\frac{s E_{2}}{Z_{2}}$

And $\mathrm{Z} 2$ on rotor side is given by,

$Z_{2}=\sqrt{R_{2}^{2}+\left(s X_{2}\right)^{2}}$

Z2- Total impedance

Apply $\mathrm{Z} 2$ in above equation

$I_{2}=\frac{s E_{2}}{\sqrt{R_{2}^{2}+\left(s X_{2}\right)^{2}}}$

$\mathrm{s}=$ slip of induction motor

power factor of the rotor circuit is

$\cos \theta_{2}=\frac{R_{2}}{Z_{2}}=\frac{R_{2}}{\sqrt{R_{2}^{2}+\left(s X_{2}\right)^{2}}}$

substituting the values $\varphi, I 2$, and $\cos \theta 2$ in the torque equation,

$T \propto E_{2} \frac{s E_{2}}{\sqrt{R_{2}^{2}+\left(s X_{2}\right)^{2}}} \times \frac{R_{2}}{\sqrt{R_{2}^{2}+\left(s X_{2}\right)^{2}}}$

Then,

$T \propto s E_{2}^{2} \frac{R_{2}}{\sqrt{R_{2}^{2}+\left(s X_{2}\right)^{2}}}$

Constant $\mathrm{K}$ is given,

$T=K s E_{2}^{2} \frac{R_{2}}{\sqrt{R_{2}^{2}+\left(s X_{2}\right)^{2}}}$

This comstant $K=\frac{3}{2 \pi n_{s}}$

Here, ns = Ns / 60 .

Torque equation becomes,

$T=s E_{2}^{2} \times \frac{R_{2}}{R_{2}^{2}+\left(s X_{2}\right)^{2}} \times \frac{3}{2 \pi n_{s}} N-m$

ns $=$ synchronous speed

In case of IM in 3 phase, The rotor copper losses,

$\mathrm{Pc}=3 \mathrm{I} 22 \mathrm{R} 2$

Here, the rotor current is known, that is

$I_{2}=\frac{s E_{2}^{0}}{\sqrt{R_{2}^{2}+\left(s X_{2}\right)^{2}}}$

Substitute $\mathrm{I} 2$ in Pc,

$P_{c}=3 R_{2}\left(\frac{s E_{2}}{\sqrt{R_{2}^{2}+\left(s X_{2}\right)^{2}}}\right)^{2}$

On simplifying $P_{c}=\frac{3 R_{2} s^{2} E_{2}^{2}}{R_{2}^{2}+\left(s X_{2}\right)^{2}}$

The ratio of $\mathrm{P} 2: \mathrm{Pc}: \mathrm{Pm}=1: \mathrm{s}:(1-\mathrm{s})$

$\mathrm{P} 2$ - rotor input,

$\mathrm{Pc}$ - copper losses in rotor,

$\mathrm{Pm}$ - mechanical power 


$$
\begin{aligned}
\frac{P_{c}}{P_{m}} & =\frac{s}{1-s} \\
\text { or } P_{m} & =\frac{(1-s) P_{c}}{s}
\end{aligned}
$$

Substitute Pc value, we get

$$
P_{m}=\frac{1}{s} \times \frac{(1-s) 3 R_{2} s^{2} E_{2}^{2}}{R_{2}^{2}+\left(s X_{2}\right)^{2}}
$$

simplify it,

$$
P_{m}=\frac{(1-s) 3 R_{2} s E_{2}^{2}}{R_{2}^{2}+\left(s X_{2}\right)^{2}}
$$

$\mathrm{Pm}=\mathrm{T} \omega$,

$$
\begin{gathered}
\omega=\frac{2 \pi N}{60} \\
\text { or } P_{m}=T \frac{2 \pi N}{60}
\end{gathered}
$$

Substituting Pm

$$
\begin{gathered}
\frac{1}{s} \times \frac{(1-s) 3 R_{2} s^{2} E_{2}^{2}}{R_{2}^{2}+\left(s X_{2}\right)^{2}}=T \frac{2 \pi N}{60} \\
\text { or } T=\frac{1}{s} \times \frac{(1-s) 3 R_{2} s^{2} E_{2}^{2}}{R_{2}^{2}+\left(s X_{2}\right)^{2}} \times \frac{60}{2 \pi N}
\end{gathered}
$$

Rotor speed N = Ns $(1-\mathrm{s})$ Substituting in $\mathrm{T}$,

$$
T=\frac{1}{s} \times \frac{(1-s) 3 R_{2} s^{2} E_{2}^{2}}{R_{2}^{2}+\left(s X_{2}\right)^{2}} \times \frac{60}{2 \pi N_{s}(1-s)}
$$

The relation between the Ns and ns given by,

$$
\frac{N_{s}}{60}=n_{s}
$$

Substitute in T,

Toeque, $T=\frac{s E_{2}^{2} R_{2}}{R_{2}^{2}+\left(s X_{2}\right)^{2}} \times \frac{3}{2 \pi N_{s}}$

$$
\text { or, } T=K s E_{2}^{2} \frac{R_{2}}{R_{2}^{2}+\left(s X_{2}\right)^{2}}
$$

Comparing both the equations, the constant $\mathrm{K}=3 / 2 \pi \mathrm{ns}$

\section{H. Switched Reluctance Motors}

The Switched Reluctance motors are categorized under variable reluctance motor with double saliency. These motors are simple and robust in construction. The rotor of SRM has no windings or permanent magnets on it. It has only laminated steel.

SRM offers high power density which makes it suitable for EVs[4]. Its robust construction makes it suitable for high speed applications. It's easy to cool the motor since the generated heat is mostly confined to the stator is shown in fig. 4 .

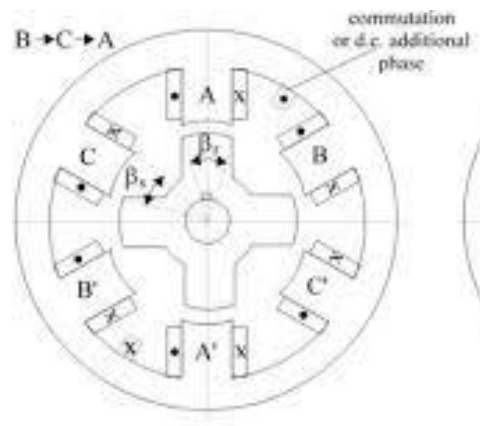

3.)

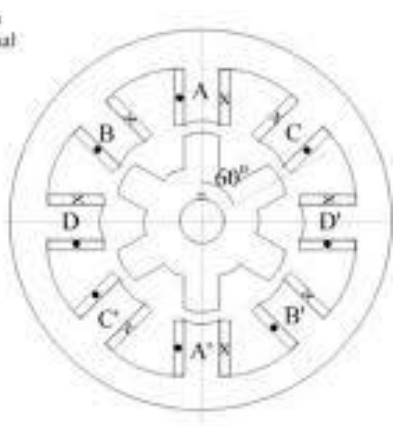

b.)
Fig. 4. Construction Model of SRM Motor

It has its own drawbacks. They are the complexity in control and increase in the switching circuit. It also has some noise issues. Low cost and high power density are the desired features when bulk manufacturing of EVs are considered. SRM will be the stiff contender of the above mentioned.

\section{Ripple In SRM Motors}

Switched reluctance motors (SRMs) can be an electrification solution for the transportation, agriculture, mining, civil and tactical sectors. SRMs are a great motor option for electric vehicles because of their low costs, high efficiency and ability to operate in harsh environments. One challenge that has held SRMs back is that they are susceptible to torque ripple, which causes noise and reduces the motor's lifespan.

\section{J. The Cause Of Torque Ripple}

SRMs take advantage of the ability of low-reluctance materials, like iron and steel, to align with magnetic fields. The SRM has phased windings on the stator and a rotor that comprises regions of low and high reluctance. When power is sent to the stator windings the magnetic flux and reluctance of the materials generate a force to align the rotor pole with the nearest stator pole. The SRM control algorithms turn stator windings on and off successively to shift the magnetic field, forcing the rotor to rotate. The challenge is that this process also creates vibration and noise due to structural deformations and magnetic torque harmonics that force the stator and rotor to interact. The interactions and vibrations that change the torque - hence torque ripple — create noise and limit the motor's lifespan.

\section{K. Designing SRMS With Reduced Torque Ripple}

These torque ripples that occur in SRM's could be greatly reduced by using a new control algorithm that could operate the SRM without torque ripple. If the motor is about to jerk in one direction, due to torque ripple, the new control algorithm will inject a signal to the motor to create a magnetic field that cancels out this jerky motion [5]. Model predictive control is represent in fig. 5 .

As a result of these active ripple cancellations prototypes were able to reduce torque ripple by $90 \%$ and noise by $50 \%$. Which is a step in the right direction and in fact a major step. 


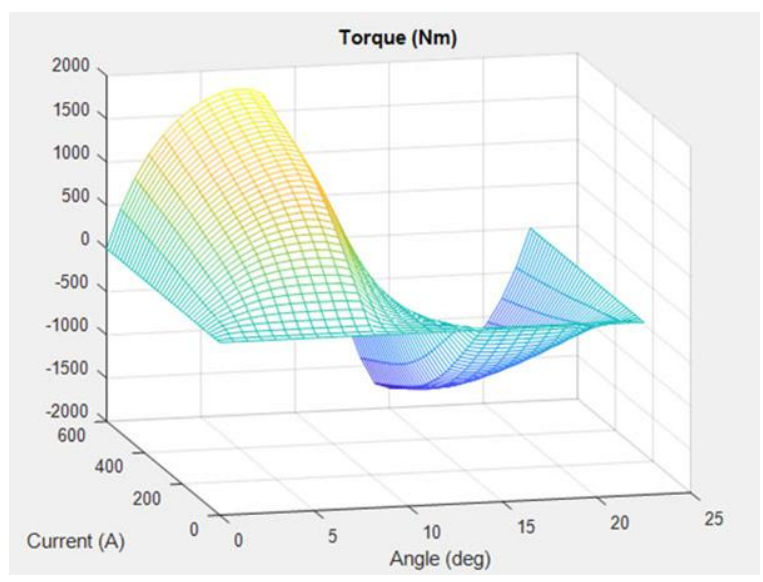

Fig. 5. Model predictive controller process

\section{RESULTS AND DISCUSSION}

DC motors are simple in construction and needs electronic systems for precise controlling. It requires high maintenance because of brushes and commutators.

Due to high starting torque, high efficiency and high-power density BLDC motors are widely preferred in electric vehicles. But costs more because of the permanent magnets and cannot be overloaded beyond certain limit.

Starting torque of three phase induction motors can be improved using control techniques but it requires complex inverter circuits for controlling. It can be used in application that requires constant speed and torque.

Construction of SRM is simple and it has no windings or permanent magnets. It offers high power density, but requires complex switching and control circuit.

\section{CONCLUSION}

This paper explained the design and modeling of electric motors and its different types that are used in the electric vehicles applications. Different type of electric motor systems had different advantages that made it a better choice in this paper for specific applications. It contains the features of the motors, parameters and control methods of the speed and torque. This paper is also included the comparison between the different motors which are used in vehicle applications.

\section{REFERENCES}

1. A. EL-Refaie, "Motors/generators for traction/propulsion applications:A review," in Electric Machines Drives Conference IIEMDC), IEEE International, pp. $490-497,2011$.

2. Jones, W.D., "Hybrids to the rescue [hybrid electric vehicles]", IEEE Spectrum, vol. 40, no. 1, 2003, pp. 70-71.

3. K.T. Chau, C.C. Chan, Chunhua Liu, "Overview of Permanent-Magnet Brushless Drives for Electric andHybrid Electric Vehicles", IEEE Tran. On IndustrialElectronics, Vol. 55, Issue 6, June 2008, pp. 22462257.

4. N. Zabihi, Member, IEEE, and R. Gouws, "A Review on Switched Reluctance Machines for Electric Vehicles," School of Electrical, Electronic, and Computer Engineering North-West University.

5. R. Suryadevara, and B. G. Fernandes, "Control techniques for torque ripple minimization in switched reluctance motor: An overview," in 8th IEEE International Conference on In Industrial and Information Systems(ICIIS), 2013, pp. 24-29.

6. Z. Yueying, W. Dafang, Z. Guifan, Y. Dongyu, and W. Yu, "Researchprogress of switched reluctance motor drive system," in InternationalConference on Mechatronics and Automation (ICMA), 2009, pp. $784-789$.
7. A.Y. Anekunu, S. P. Chowdhury, and S. Chowdhury, "A review of research and development on switched reluctance motor for electric vehicles," in Power and Energy Society General Meeting (PES), 2013, pp. 1-5.

8. J. Li and Y. Cho, "Investigation into reduction of vibration and acoustic noise in switched reluctance motors in radial force excitation and frame transfer function aspects," IEEE Transactions on Magnetics, vol. 45, no. 10, pp. 4664-4667, 2009.

9. A. Emadi, Y.J. Lee, K. Rajashekara, "Power electronics and motor drives in electric, hybrid electric ,and plug-in hybrid electric vehicles," IEEE Transactions on Industrial Electronics 2008, pp.55:2237-45.

10. M. Simon Darsingh, Dr. Sanjay S Chaudhary, "Impedance Source Based Multi Phase Inverter Fed Variable Speed PMBLDC Motor Using Advance controller for Torque Ripple Minimization,", International Journal of MC Square Scientific Research Vol.8, No.1,pp.109-127, 2016

\section{AUTHORS PROFILE}

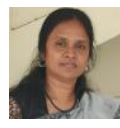

S. Jensie Anita is an Assistant Professor in the department of EEE at AarupadaiVeedu Institute of Technology. She received her Bachelor Degree in Electrical and Electronics Engineering, Mookambigai Engineering College and Master's Degree in Power Electronics and Drives from Anna University. She has participated and presented a paper in 4th ASEAN Smart Grid Congress, SGTech, Thailand. She is a research scholar in the Department of Electrical and Electronics Engineering,VinayakaMissions Research Foundation.

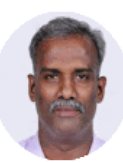

Dr. K. Boopathy received the B.E from Madras University (Electrical \& Electronics Engineering) in 1999, M.E in Electronic Engineering from Anna University (MIT campus) in 2003, and Ph.D in power electronics from Anna University, Chennai in 2012. Currently he is working as a Professor in Dept. of EEE AVIT-VMRF, OMR Chennai. He has published several National and International Journals and Conferences. His area of interest is Power Electronics and Drives, soft computing technique application to power electronics and electrical machines. E-mail: boopathyk@avit.ac.in. 